\title{
HUBUNGAN INDEKS MASSA TUBUH DAN LINGKAR PINGGANG DENGAN TEKANAN DARAH LAKI-LAKI DEWASA
}

\author{
Tamariani Manullang, Tetes Wahyu, Darwis \\ Politeknik Kesehatan Kementerian Kesehatan Bengkulu, Jurusan Gizi, \\ Jalan Indragiri Nomor 03 Padang Harapan Kota Bengkulu \\ tamarianimanullang@gmail.com
}

\begin{abstract}
Prevalence of hypertension in adult males was highest in Puskesmas Basuki Rahmat (16.2\%) as many as 648 cases of hypertension patients which has increased compared to 2012 by $12 \%$ in cases of hypertension totaled 482 patients ((Dinkes Kota, 2013). This study aims to determine the relationship of body mass index (BMI) and waist circumference (WC) with systolic blood pressure (BP) in adult males in Puskesmas Basuki Rahmat Bengkulu City in 2015. The study design was descriptive analytic with cross sectional approach. Study location was in Puskesmas Basuki Rahmat City of Bengkulu. Samples were selected using purposive sampling totalling 68 people. Criterias sample were being adult males who occupied in Puskesmas Basuki Rahmat City of Bengkulu, aged $\geq 18$ years, agreed to be interviewed, and able to communicate actively. Data were obtained include BMI, WC and systolic BP adult males and processed using computer software with pearson correlation analysis. The results showed that there was relationship between BMI and systolic BP ( $p=0.0005 ; \mathrm{r}=0.395)$; between WC and systolic $\mathrm{BP}(\mathrm{p}=0.004$ and $\mathrm{r}=$ 0.347 ) in adult males. This study concluded that there was relationship between BMI and WC with systolic BP in adult males in Puskesmas Basuki Rahmat Bengkulu City in 2015.
\end{abstract}

Keywords : Body Mass Index, Waist Circumference and Blood Pressure

Abstrak : Data Dinas Kesehatan (Dinkes) Kota Bengkulu tahun 2013 menunjukkan prevalensi hipertensi pada laki-laki dewasa yang tertinggi berada di Puskesmas Basuki Rahmad yaitu sebesar 16,2\% dengan kasus hipertensi sebanyak 648 penderita. Prevalensi ini mengalami peningkatan dibandingkan dengan tahun 2012 sebesar $12 \%$ dengan kasus hipertensi pada laki-laki berjumlah 482 penderita (Dinkes Kota Bengkulu, 2013). Penelitian ini bertujuan mengetahui hubungan indeks massa tubuh (IMT) dan lingkar pinggang (LP) dengan tekanan darah (TD) laki-laki dewasa di wilayah kerja Puskesmas Basuki Rahmad Kota Bengkulu tahun 2015. Desain penelitian adalah desktiptif analitik dengan pendekatan cross sectional. Lokasi penelitian di wilayah kerja Puskesmas Basuki Rahmad Kota Bengkulu. Sampel dipilih menggunakan purposive sampling yang berjumlah 68 orang. Kriteria sampel penelitian yaitu menetap di wilayah kerja Puskesmas Basuki Rahmad Kota Bengkulu, berusia $\geq 18$ tahun, bersedia untuk diwawancarai, mampu berkomunikasi dengan aktif dan berjenis kelamin laki-laki. Data diperoleh meliputi IMT, LP dan TD sistolik lakilaki dewasa yang diolah menggunakan perangkat lunak komputer dengan analisis pearson correlation. Hasil penelitian menunjukkan ada hubungan antara IMT dengan TD sistolik laki-laki dewasa $(\mathrm{p}=0,0005 ; \mathrm{r}=0,395)$ dan ada hubungan antara LP dengan TD sistolik laki-laki dewasa $(p=0,004$ dan $r=0,347)$. Penelitian ini menyimpulkan ada hubungan antara IMT dan LP dengan TD sistolik laki-laki dewasa di wilayah kerja Puskesmas Basuki Rahmad Kota Bengkulu tahun 2015.

Kata Kunci : Indeks Massa Tubuh, Lingkar Pinggang, dan Tekanan Darah 
Kemajuan perekonomian sebagai dampak dari pembangunan di negara-negara berkembang menyebabkan perbaikan taraf hidup masyarakat. Meningkatnya taraf hidup masyarakat membawa pula perubahan pola penyakit yang ada, terutama pada penyakit yang berhubungan dengan gaya hidup seseorang contohnya penyakit kardiovaskuler (Supriyono, 2008).

Meningkatnya prevalensi penyakit kardiovaskuler setiap tahun menjadi masalah utama di negara berkembang dan negara maju. Berdasarkan data Global Burden of Disease (GBD) tahun 2000, 50\% dari penyakit kardiovaskuler disebabkan hipertensi. Tekanan darah tinggi atau yang sering disebut dengan hipertensi merupakan salah satu faktor risiko penyakit kardiovaskuler dengan prevalensi dan kematian yang cukup tinggi terutama di negara-negara maju dan di daerah perkotaan di negara berkembang sepertinya halnya di Indonesia (Anggraini, 2009) .

Berdasarkan hasil Riset Kesehatan Dasar (Riskesdas) tahun 2013, Prevalensi hipertensi di Indonesia yang diperoleh melalui pengukuran pada umur $\geq 18$ tahun sebesar 25,8 persen, tertinggi di Bangka Belitung (30,9\%). Sedangkan Provinsi Bengkulu memiliki prevalensi yang cukup tinggi yaitu sebesar 21,6\% , hal ini menunjukkan bahwa hipertensi masih menjadi masalah di Provinsi Bengkulu. Prevalensi hipertensi meningkat sejalan dengan perubahan gaya hidup seperti merokok, obesitas, inaktivatas fisik, dan stress psikososial (Suhardi dkk, 2011).

Data Dinas Kesehatan Kota Bengkulu tahun 2013 menunjukan bahwa prevalensi hipertensi pada laki-laki dewasa yang tertinggi berada di Puskesmas Basuki Rahmad yaitu sebesar 16,2 \% dengan kasus hipertensi 648 penderita. Hal ini berarti prevalensi hipertensi pada laki-laki di Puskesmas Basuki Rahmad mengalami peningkatan dibandingkan dengan tahun 2012 yaitu sebesar $12 \%$ dengan kasus hipertensi pada laki-laki berjumlah 482 penderita (Profil Dinkes Kota Bengkulu, 2013). Berdasarkan data dari Puskesmas Basuki Rahmad jumlah laki-laki yang menetap di wilayah kerja Puskesmas tersebut bulan September 2014 sebanyak 18.337 orang.
Terdapat berbagai metode pengukuran antropometri tubuh yang dapat digunakan sebagai skrining obesitas. Metode tersebut antara lain pengukuran indeks massa tubuh, lingkar pinggang, lingkar panggul, lingkar lengan, serta perbandingan lingkar pinggang dan lingkar panggul. Lingkar pinggang merupakan pengukur distribusi lemak abdominal yang mempunyai hubungan erat dengan indeks massa tubuh. Indikator status gizi yang dikaitkan dengan tekanan darah antara lain Indeks Massa Tubuh (IMT), Rasio Lingkar Terhadap Tinggi Badan (RLPTB), Lingkar Pinggang (LP), dan Lingkar Leher (LL) (Zhou Z, 2008).

Tekanan darah tinggi atau hipertensi adalah kondisi medis dimana terjadi peningkatan tekanan darah secara kronis. Hipertensi berarti tekanan darah tinggi di dalam pembuluh darah arteri yang dapat menyebabkan meningkatnya risiko penyakit stroke, gagal jantung, serangan jantung dan kerusakan ginjal.

Tekanan darah sistolik normal adalah antara 90 sampai $120 \mathrm{~mm} / \mathrm{Hg}$. Tekanan darah diatas 140/90 mmHg termasuk tekanan darah tinggi (Cynthia L, 2009). Penyakit hipertensi lebih akrab disebut sebagai penyakit darah tinggi. Penyakit ini terjadi tanpa gejala yang dapat meningkatkan risiko seseorang terkena penyakit stroke, aneurisma, gagal jantung, serangan jantung, sampai kerusakan ginjal (Ridwan, 2009).

Status gizi yang tidak seimbang merupakan akibat dari kebiasaan buruk. Kelebihan gizi yang dimulai pada usia 45 tahun keatas biasanya berhubungan dengan kemakmuran dan gaya hidup. Dengan kondisi ekonomi yang membaik dan tersedianya berbagai makanan siap saji yang enak, nikmat, dan kaya akan energi terutama sumber lemak dan karbohidrat, maka terjadi asupan makanan dan zat gizi yang melebihi kebutuhan tubuh. Keadaan kelebihan gizi ini akan membawa pada keadaan obesitas. Perubahan status gizi yang ditandai dengan peningkatan berat badan dapat secara langsung mempengaruhi perubahan tekanan darah (Riyadi, 2007).

Banyak faktor yang berperan untuk terjadinya hipertensi meliputi faktor risiko 
yang tidak dapat dikendalikan (mayor) dan faktor risiko yang dapat dikendalikan (minor). Faktor mayor seperti keturunan, jenis kelamin, ras, dan umur. Sedangkan factor minor yaitu olahraga, konsumsi makanan, alkohol, stress, dan kelebihan berat badan (obesitas) (Palmer, 2007). Menurut Kozier et al (2009), obesitas merupakan faktor predisposisi hipertensi baik pada anak-anak maupun dewasa. Banyak penelitian membuktikan adanya hubungan antara indeks massa tubuh dengan kejadian hipertensi dan diduga peningkatan berat badan memainkan peranan penting pada mekanisme timbulnya hipertensi pada orang dengan obesitas (Kozier et al, 2009).

Berdasarkan National Health and Nutrition Examination Survey (NHANES) III, prevalensi hipertensi pada orang yang memiliki IMT $>30 \mathrm{~kg} / \mathrm{m}^{2}$ adalah $42 \%$ pada pria dan $38 \%$ pada wanita dibandingkan dengan prevalensi hipertensi pada orang yang memiliki IMT normal $<25 \mathrm{~kg} / \mathrm{m}^{2}$ adalah $15 \%$ pada pria dan wanita (Brown CD, 2000). Resiko peningkatan tekanan darah pada orang yang overweight dua sampai enam kali lebih besar daripada orang yang memiliki berat badan normal (NIH, 2004). Dilihat dari data yag diperoleh Riskesdas tahun 2013 prevalensi obesitas dan berat badan lebih di Bengkulu cukup tinggi yakni sekitar $>20 \%$ (Riskesdas, 2013). Individu dengan kelebihan berat badan $20 \%$ memiliki risiko hipertensi 38 kali lebih tinggi dibandingkan dengan individu dengan berat badan normal (Suarthana dkk, 2001).

Adapun faktor penting yang mengakibatkan hipertensi adalah lingkar pinggang. Lingkar pinggang adalah ukuran antropometri yang dapat digunakan untuk menentukan obesitas sentral, dan kriteria untuk Asia Pasifik yaitu $\geq 90 \mathrm{~cm}$ untuk pria , dan $\geq 80 \mathrm{~cm}$ untuk wanita. Lingkar pinggang dikatakan sebagai indeks yang berguna untuk menentukan obesitas sentral dan komplikasi metabolik yang terkait. Terdapat hubungan yang signifikan antara lingkar pinggang dengan tekanan darah, rata-rata lingkar pinggang yang $>90 \mathrm{~cm}$ untuk laki-laki dan $>80 \mathrm{~cm}$ untuk perempuan memiliki tekanan darah yang lebih tinggi (Jalal, 2006).
Penelitian ini bertujuan mengetahui hubungan indeks massa tubuh (IMT) dan lingkar pinggang (LP) dengan tekanan darah (TD) laki-laki dewasa di wilayah kerja Puskesmas Basuki Rahmad Kota Bengkulu tahun 2015.

\section{BAHAN DAN CARA KERJA}

Metode penelitian dilakukan observasional analitik dengan menggunakan desain penelitian deskriptif analitik dengan pendekatan cross sectional. Populasi yang digunakan adalah seluruh laki-laki dewasa di Wilayah Kerja Puskesmas Basuki Rahmat di Kota Bengkulu berjumlah 68 responden yang diambil berdasarkan teknik pengambilan sampel secara purposive sampling dan telah memenuhi kriteria yang telah ditentukan.

Analisis univariat akan disajikan dalam bentuk tabel dan analisis secara deskriptif dengan persentase. Analisis bivariat menyajikan hubungan antara dua variabel numerik/nominal yang dapat dihasilkan menjadi dua jenis, yaitu derajat atau keeratan hubungan dengan menggunakan uji Pearson Korelasi. Dasar pengambilan keputusan adalah Ho diterima jika $\mathrm{p}>0,05$ dan Ho ditolak jika $\mathrm{p}<$ 0,05 .

\section{HASIL}

Tabel 1 Distribusi Frekuensi IMT dan Lingkar Pinggang Laki-laki Dewasa,

\begin{tabular}{cccc}
\hline Variabel & $\begin{array}{c}\text { Mean } \\
\left.\mathbf{g} / \mathbf{m}^{\mathbf{2}}\right)\end{array}$ & Min $\left(\mathbf{k g} / \mathbf{m}^{\mathbf{2}}\right)$ & $\begin{array}{c}\text { Maks } \\
\left(\mathbf{k g} / \mathbf{m}^{\mathbf{2}}\right)\end{array}$ \\
\hline IMT & 21,5 & 16,2 & 31,6 \\
LP & 78,6 & 61,8 & 94,2 \\
\hline
\end{tabular}

Hasil penelitian pada tabel 1 yang telah dilakukan didapatkan bahwa rata-rata indeks massa tubuh laki-laki dewasa di wilayah kerja puskesmas Basuki Rahmad adalah 21,50 $\mathrm{kg} / \mathrm{m}^{2}$ dengan indeks massa tubuh terendah yaitu $16,2 \mathrm{~kg} / \mathrm{m}^{2}$ dan indeks massa tubuh tertinggi yaitu $31,6 \mathrm{~kg} / \mathrm{m}^{2}$. Persentase laki-laki dewasa yang memiliki IMT melebihi batas normal adalah 23,5\% dan laki-laki dewasa yang memiliki IMT dibawah batas normal $10,2 \%$.

Hasil penelitian yang telah dilakukan didapatkan bahwa rata-rata lingkar pinggang 
laki-laki dewasa di wilayah kerja puskesmas Basuki Rahmad adalah 78,6 cm atau dalam kategori normal. Lingkar pinggang terendah yaitu $61,8 \mathrm{~cm}$ dan lingkar pinggang tertinggi yaitu $94,2 \mathrm{~cm}$. Persentase laki-laki dewasa yang memiliki lingkar pinggang tidak normal atau diatas $90 \mathrm{~cm}$ adalah $14,7 \%$.

Hasil penelitian pada tabel 2 yang telah dilakukan didapatkan bahwa rata-rata tekanan darah sistolik laki-laki dewasa di wilayah kerja puskesmas Basuki Rahmad adalah 121,6 $\mathrm{mmHg}$, dengan tekanan darah sistolik terendah yaitu $80 \mathrm{mmHg}$ dan tekanan darah sistolik tertinggi yaitu $150 \mathrm{mmHg}$. Presentase lakilaki dewasa yang memiliki tekanan darah tinggi adalah 44,1 \% dan presentase laki-laki dewasa yang memiliki tekanan darah rendah adalah $17,6 \%$.

Tabel 2. Distribusi Frekuensi Tekanan Darah Sistolik Laki-laki Dewasa

\begin{tabular}{cccc}
\hline Variabel & $\begin{array}{c}\text { Mean } \\
\mathbf{n H g})\end{array}$ & Min $(\mathbf{m m H g})$ & $\begin{array}{c}\text { Maks } \\
(\mathbf{m m H g})\end{array}$ \\
\hline $\mathrm{TD}$ & 78,6 & 61,8 & 94,2 \\
\hline
\end{tabular}

Berdasarkan tabel 3 didapatkan bahwa ada hubungan ( $\mathrm{p}$ value $=0,000)$ antara indeks massa tubuh dengan tekanan darah sistolik dengan hubungan lemah berpola positif $(0,395)$ artinya semakin besar indeks massa tubuh responden maka semakin tinggi pula tekanan darah sistolik pada laki-laki dewasa di Wilayah Kerja Puskesmas Basuki Rahmat Kota Bengkulu.

Tabel 3. Hubungan Indeks Massa Tubuh dan Lingkar Pinggang dengan Tekanan Darah Sistolik

\begin{tabular}{ccc}
\hline Variabel & $\begin{array}{c}\text { Nilai r Pearson } \\
\text { Correlation }\end{array}$ & Nilai p \\
\hline $\begin{array}{c}\text { Indeks Massa } \\
\text { Tubuh }\end{array}$ & 0,395 & 0,0005 \\
\hline $\begin{array}{c}\text { Lingkar } \\
\text { Pinggang (LP) }\end{array}$ & 0,347 & 0,004 \\
\hline
\end{tabular}

Berdasarkan tabel 3 bahwa ada hubungan ( $\mathrm{p}$ value $=0,004$ ) antara lingkar pinggang dengan tekanan darah sistolik dengan hubungan lemah berpola positif $(0,347)$ artinya semakin besar lingkar pinggang responden maka semakin tinggi pula tekanan darah sistolik pada laki-laki dewasa di wilayah kerja Puskesmas Basuki Rahmad Kota Bengkulu.

\section{PEMBAHASAN}

Hubungan Indeks Massa Tubuh dengan Tekanan Darah Sistolik pada Laki-Laki Dewasa

Berdasarkan hasil penelitian dari 68 responden, 16 responden memiliki indeks massa tubuh tidak normal/lebih yang artinya $23,3 \%$ responden mengalami berat badan yang berlebih dengan IMT diatas $22,9 \mathrm{~kg} / \mathrm{m}^{2}$.

Sebagaimana teori yang dikemukanan Sudoyo (2006) yang menyatakan bahwa obesitas merupakan salah satu faktor risiko yang sering dialami penderita hipertensi terutama di kalangan usia muda. Berat badan yang berlebih pada penderita obesitas akan membuat seseorang susah bergerak secara bebas, jantung harus bekerja lebih keras untuk memompa darah agar bisa lebih mudah menggerakkan tubuh.

Pada penelitian ini hasil bivariat dengan uji korelasi pada IMT didapatkan ada hubungan antara IMT dengan tekanan darah darah sistolik yang ditunjukkan dengan nilai $\mathrm{p}$ value $(0,000)<0,05$. Menurut Muhammaddun (2010), indeks massa tubuh berkorelasi langsung dengan tekanan darah, resiko untuk menderita hipertensi pada orang gemuk (Obesitas) 5 kali lebih tinggi dibandingkan dengan seseorang yang berat badannya normal. Pada penderita hipertensi ditemukan sekitar 20-30\% memiliki berat badab lebih. Prevalensi pada tekanan darah tinggi pada orang dengan Indeks Massa Tubuh >30 adalah $38 \%$ untuk pria dan $32 \%$ untuk wanita, dibandingkan dengan prevalensi $18 \%$ untuk pria dan $17 \%$ untuk wanita yang memiliki IMT $<25$.

Pengukuran antropometri seperti berat badan, tinggi badan, IMT, pengukuran tebal lipatan kulit pada bagian tubuh tertentu dapat menentukan status kegemukan seorang. Indeks massa tubuh merupakan hasil pengukuran berat badan dibagi tinggi badan kuadrat dalam satuan meter. Hasil pengukuran indeks massa tubuh yang berlebih menggambarkan kegemukan atau lebihnya lemak pada seluruh tubuh. Hal tersebut mempengaruhi tekanan darah pada pembuluh darah saat terjadi kontraksi pada otot jantung atau tekanan darah 
sistolik Berat badan merupakan faktor determinan pada tekanan darah.

Terapi non farmakologis atau upaya gizi dapat diberikan pada laki-laki dewasa yang mengalami hipertensi tahap awal, diantaranya menurunkan berat badan, meningkatkan aktivitas dan olah raga, mengurangi konsumsi makanan tinggi natrium, serta manajemen stres. Penerapan diet Dietary Approaches to Stop Hypertension (DASH) pada laki-laki dewasa juga dapat memberikan efek yang signifikan terhadap penurunan tekanan darah. Diet DASH meliputi memperbanyak konsumsi sayur, buah, kacang-kacangan, gandum utuh, susu, produk susu rendah lemak, ikan, unggas, dan mengurangi konsumsi makanan yang mengandung lemak jenuh dan gula.

\section{Hubungan Lingkar Pinggang dengan Tekanan Darah pada Laki-Laki Dewasa}

Berdasarkan hasil penelitian dari 68 responden, 32 responden memiliki lingkar pinggang lebih dari $80 \mathrm{~cm}$ yang artinya $47 \%$ responden mengalami berat badan yang berlebih atau overweight. Salah satu faktor pencetus tingginya tekanan darah adalah obesitas. Lingkar pinggang berkorelasi kuat dengan obesitas sentral dan risiko kardiovaskuler. Lingkar pinggang terbukti dapat mendeteksi obesitas sentral dan sindroma metabolik dengan ketepatan yang cukup tinggi dibandingkan indeks massa tubuh (IMT) dan lingkar panggul. WHO mengeluarkan definisi sindroma metabolik yang salah satunya adalah tekanan darah. Berdasarkan hasil penelitian, rata-rata responden yang memiliki lingkar pinggang $>90 \mathrm{~cm}$ untuk laki-laki dan $>80 \mathrm{~cm}$ untuk perempuan memiliki tekanan darah yang tinggi (Jalal, 2006). Pada remaja laki-laki indikator yang paling berhubungan de-ngan tekanan darah sistolik adalah IMT, dan tekanan darah diastolik adalah lingkar pinggang. Pada remaja perempuan indikator yang paling berhubungan dengan TDS dan TDD adalah Lingkar Lengan (Novianingsih, 2012).

Banyaknya penumpukan lemak disekitar abdomen sering berhubungan secara signifikan dengan sidroma metabolik yang menjadi penyebab penyakit kardiovaskuler. Penelitian yang dilakukan oleh The National Heart,
Lung, and Blood Institute tahun 2005 menghasilkan data bahwa pasien tekanan darah tinggi lebih banyak ditemukan pada individu dengan obesitas sentral dibandingkan dengan obesitas general. Pengukuran lingkar pinggang dan rasio lingkar pinggang pinggul merupakan teknik antropometri yang paling baik untuk menentukan timbunan lemak disekitar abdomen atau disebut juga obesitas sentral.

Hasil uji statistik menggunakan uji korelasi Pearson, menunjukkan bahwa terdapat korelasi yang signifikan antara lingkar pinggang dengan tekanan darah sistolik yang ditunjukkan dengan nilai $\mathrm{p}$ value $(0,004)<$ 0,05 . Hasil penelitian ini sejalan dengan hasil penelitian yang dilakukan oleh Putri Rahayu (2011) di Malang yang menyatakan ada hubungan yang signifikan $(\mathrm{P}=0,046)$ antara lingkar pinggang dengan tekanan darah sistolik, dengan kekuatan korelasi sangat lemah $(\mathrm{r}=$ 0,207) dan arah korelasi positif.

Lingkar pinggang yang berlebih menggambarkan kumpulan lemak abdominal berlebih yang terdapat di daerah abdomen. Obesitas abdominal berkaitan erat dengan penyakit kardiovaskular. Saat berat badan seseorang lebih tinggi dari normal, biasanya disebabkan oleh lemak berlebih (dalam bentuk kolesterol) dalam tubuh. Hal ini bisa disimpan di sepanjang dinding arteri, sehingga menyebabkan penyempitan. Akibatnya kerja jantung harus memompa lebih keras lagi agar darah bisa melewati pembuluh arteri, dan selanjutnya terjadi peningkatan tekanan darah khususnya tekanan darah sistolik karena tekanan darah sistolik adalah tekanan keatas pembuluh arteri akibat denyutan jantung (Kartika, 2008).

Lingkar Pinggang dikatakan jumlah lemak intraabdominal. Jaringan lemak intrabdominal terdiri dari lemak viseral atau lemak intraperitoneal yang terdiri dari lemak omental dan mesenterial serta masa lemak retro-peritoneal. Lingkar pinggang berkorelasi baik dengan indeks massa tubuh baik laki-laki maupun perempuan (Irene, 2014).

Pada seseorang yang memiliki lingkar pinggang diatas normal tahanan perifer akan berkurang atau menjadi normal, sedangkan aktifitas saraf simpatis meninggi, dengan aktifitas renin plasma yang rendah. Lingkar 
pinggang yang tidak normal dapat mem-perbesar kemungkinan munculnya faktor-faktor resiko lainnya dam merupakan bahaya yang serius untuk kesehatan (Jalal, 2006)

Hipertensi dapat dikendalikan atau dicegah dengan melakukan olahraga yang cukup. Dengan olahraga yang cukup, peredaran darah akan menjadi lancar serta membakar lemak dan tidak menyebabkan obesitas sehingga lingkar pinggang menjadi normal, tidak merokok, tidak meminum alcohol, istirahat yang cukup dan mengatur pola makan (Muhammadun, 2010).

\section{DAFTAR RUJUKAN}

Anggraini D. Ade (2009). Faktor-faktor yang berhubungan dengan kejadian hipertensi pada pasien yang berobat di poliklinik dewasa puskesmas bangkinang periode januari-juni

Andarini. S. 2012. Hubungan Intake Calcium Dan Magnesium Dengantekanan Darah Pada Usia Dewasadi Kecamatan Kedung kandang Kotamalang tahun 2012. Malang

Beevers, D.G. 2002. Seri Kesehatan Bimbingan Dokter Pada Tekanan Darah. Dian Rakyat :Jakarta

Corwin, Elizabeth J. Hanbook of Pathophysiology (1996). Pendit, BU. 2001. Buku saku Patofisiologi. Jakarta : Penerbit Buku Kedokteran EGC

Dhianningtyas, Yunita \& Hendrati, Lucia Y. 2006. 'Risiko Obesitas, kebiasaan merokok, dan konsumsi garam terhadap kejadian hipertensi pada usia produktif'. The Indonesian Journal of Public Health Vol. 2 No. 3

Dinkes Kota Bengkulu, 2013. Profil Kesehatan Kota Bengkulu. Dinkes Kota Bengkulu : Bengkulu

Gardner, Samuel. 2007. Smart Treatment For High Blood Preassure. Jakarta: Pustaka Publisher

Moudy Sumayku, Irene, Karel P, MCP Wongkar.2014. Hubungan Indeks Massa Tubuh Dan Lingkar Pinggang dengan Tekanan Darah Pada Mahasiswa Fakultas Kedokteran Sam Ratulangi.Jurnal e-Clinic, Volume 2,No. 2.

Jalal, Fasli (2006).Hubungan Lingkar Pinggang Dengan Kadar Gula, Trigliserida Dan Tekanan Darah Pada Etnis Minang di Kabupaten Pariaman, Sumatera Barat.

Lili \& Tantan, 2007. 100 Question \& Answer Hipertensi. PT Elex Media Komputindo:Jakarta

Lilyana, 2008. Faktor-Faktor Risiko Hipertensi Pada Jamaah Pengajian Majelis Dzikir SBY Nurulsallam Tahun 2008. Jakarta

Muniroh, Lailatul, Wirjatmadi, Bambang \& Kuntoro. 2007. 'pengaruh pemberian jus buah belimbing dan mentimun terhadap penurunan tekanan darah sistolik dan diastolik penderita hipertensi'. The

\section{KESIMPULAN}

Hasil penelitian disimpulkan bahwa ada hubungan IMT dengan TDS laki-laki dewasa dan Ada hubungan LP dengan TDS laki-laki dewasa di wilayah kerja Puskesmas Basuki Rahmad. Diharapkan kepada tenaga pelaksana gizi puskesmas dapat meningkatkan surveilan secara berkala mengenai indeks massa tubuh dan lingkar pinggang dengan tekanan darah laki-laki dewasa di wilayah kerja Puskesmas Basuki Rahmad Kota Bengkulu agar dapat mengurangi risiko hipertensi.

Indonesian Journal of Public Health, Vol.4, No. 1

National Institutes of Health. National Heart. Lung and Blood Institute. National High Blood Pressure Education Program. The Seventh Report Of the Joint Natinal Committe On Prevention, Ditection, Evaluation, and Treatment Of High Blood Preasure. NIH Publication No. 04-5230 August 2004.

Notoadmojo. S. 2005.Ilmu Kesehatan Masyarakat. Jakarta : Rineka Cipta

Novianingsih Eva, Apoini Kartini.2012. Hubungan Antara Beberapa Indikator Status Gizi Dengan Tekanan Darah Remaja. Journal Of Nutritional College Vol.1 No. 1 Hal :169-175

Muhammadun,2010. Hidup Bersama Hipertensi. Penerbit In Books : Yogyakarta

Palmer \& Williams. 2007. Tekanan Darah Tinggi. Jakarta : Erlangga

Pradono, J. 2010. Faktor-Faktor Yang Mempengaruhi Terjadinya Hipertensi Di Daerah Perkotaan. Jakarta: Gizi Indonesia

Rahayu, 2012. Faktor Resiko Hipertensi pada Masyarakat Rw 01 Srengseng Sawah Kecamatan Jagakarsa Kota Jakarta Selatan. Universitas Indonesia: Depok

Riset Kesehatan Dasar (Riskesdas). 2013. Badan Penelitian Dan Pengembangan Kesehatan. Kementrian Kesehatan RI.

Riyadi A, Wiyono P, Budiningsari DR. 2007. Asupan Gizi dan Status Gizi Sebagai Faktor Risiko Hipertensi Esensial Pada Lansia di Puskesmas Curup dan Puskesmas Perumnas Kabupaten Rejang Lebong Provinsi Beng Utami, 2009. Solusi Sehat Mengatasi Hipertensi. PT. Agromedia Pustaka: Jakarta

Wanget al.2007. Whole-and Refine-Grain Intakes and the Risk of Hypertension in Women. Am J Clin Nutr 86 (2): 472-479

Yahya, F.A.2011. Dalam jurnal Hipertensi, Jangan Biarkan Ganggu Jantung. Diakses dari: 
Http://Localhost/D:/Tesis/Hipertensi/A. Fauzi Yahya Dokter Spesialis Penyakit Jantung Dan Pembuluh Darah.htm

Yogiantoro, M., 2009. Hipertensi Esensial. In: A.W. Sudoyo, B. Setiyohadi, I.Alwi (eds.), Buku Ajar Ilmu Penyakit Dalam Jilid II. 5th ed. Jakarta Pusat: Interna Publishing Jurnal Gizi Klinik Vol. 4 No. 1 Hal 43-51

Kartika, Ratna Dwi. (2008) Hubungan Indikator Obesitas Abdominal Dengan Tekanan Darah. Undergraduate thesis, Program Studi Ilmu Gizi.

Suarthana E, Tarigan IFA, Kaligis MF, Sandra A, Purwanta D, dan Hadi S. Prevalensi Hipertensi
Pada Ibu Rumah Tangga dan Faktor-faktor Gizi yang berhubungan di Kelurahan Utan Kayu Jakarta Timur. Majalah Kedokteran Indonesia 2001; 15: 158-163.

Sheps, Sheldon G. 2005. Mengatasi Tekanan Darah Tinggi. Jakarta : PT Intisari Mediatama

Supariasa. 2002. Penilaian Status Gizi. Jakarta : EGC

Supriyono, M. 2008. Faktor-faktor resiko yang berpengaruh terhadap kejadian penyakit jantung koroner pada kelompok usia $\leq 45$ tahun. UNDIP, Semarang

Utami, P.2009. Solusi Sehat Mengatasi Hipertensi. PT Agromedia Pustaka: Jakarta 